minimize opportunities for personal interaction that some respondents feel is necessary to facilitate spontaneity in discussions and lead to a sense of isolation.

The results of both of these surveys will identify the factors that will aid further progress and potential course delivery. The subject content of future CPD required by the information workers will be ascertained and a model for future delivery proposed. We are intending to follow up a small number of respondents to both surveys in order to explore in greater depth some of the issues raised. These findings will form part of the final report which is due to be delivered to the British Library in September of this year. This report will then be made available to the profession.

\title{
References
}

1. John Martyn, J., Vickers, P. and Feeney, M. (ed), Information 2000, London, Bowker-Saur, 1990, p70.

2. Universities Funding Council Circular 8/92. London, 1992.

3. Dorairaju, G., Hämäläinen, M., Krol, J., Mikhi, J., Pätynen, E., Virtamo, J., Alexander, G., Computer support for resource-based collaborative learning at a distance: OU XT001 and the Finnish experience. Proc. Hypermedia in Vaasa '94. Vaasa Institute of Technology, 1994.

4. MacDougall, J., Lewins, H., Tseng, G., Continuing education and training opportunities in librarianship. (British Library Research Paper 74) London: British Library, 1990.

\section{Benchmarking - BLRD\&D funded research at Loughborough University of Technology}

\author{
PENNY GARROD \\ Department of Information and Library Studies \\ Loughborough University
}

\section{Introduction}

Benchmarking is a term which is being used increasingly in the media. The language and trends of the commercial world often pass into common usage in this way. Professor Tony Bendell, author of Benchmarking for competitive advantage refers to a 'benchmarking boom'(1). The problem with the term 'benchmarking' is that it is concrete, not abstract (unlike 'quality'), so it is easier to perceive in terms of products and industry, but less easy to imagine in the context of a service environment. An article in The Economist coined the memorable title 'First find your bench', which highlights the problem ${ }^{(2)}$. Benchmarking smacks of industrial practice. It connotes production lines, inspection, and above all a tangible product which can easily be improved with practical results.

Consequently, there are many definitions and descriptions of benchmarking, and their appeal depends on whether your preference is for the simple, snappy definition or for the more expansive, explanatory style. Definitions often originate from management consultants and Quality 'gurus', and may meet with a degree of scepticism and scorn.

The Department of Trade and Industry's (DTI) booklet on benchmarking contains a useful 
explanation which highlights the aims of benchmarking, whilst dispensing with the excesses of 'management speak':

'The real goal is to build on the success of others to improve future performance. By benchmarking on a continuing basis, you are always researching current best practice, not dated ideas. Benchmarking is always carried out with the goal of putting improvements into action'(3).

Benchmarking is all about survival during difficult times. It is concerned with quality; it applies to services as much as to tangible products. Its application to the service sector is now being acknowledged, with customer service rating the most benchmarked function in the commercial sector at $72 \%(4)$. This is because benchmarking is primarily concerned with the role of the customer. It is built on the premise that in times of fierce competition and depleted resources, those who listen to, and act upon, the needs of their customers tend to succeed.

\section{Benchmarking and the library and information services sector}

In the light of the increasing interest in the field of benchmarking, the Department of Information and Library Studies at Loughborough University is currently conducting research into the potential role of benchmarking in library and information services. The duration of the project is one year (December 1994 - December 1995), and it is funded by the British Library Research and Development Department.

\section{Aims and objectives}

The aim of the project is to assess prevailing attitudes and practices relating to benchmarking in the academic and industrial library sectors. Benchmarking is seen to be a measurement tool allowing gaps in performance to be identified. Comparisons can then be made with other organizations whose processes are similar, so that best practice for a particular process can be established. Benchmarking partners can be from any organization with comparable processes. The 'benchmark' is the point of reference by which performance is judged or measured. In a library and information services context it might involve measuring the effectiveness of a process which is considered critical to customer satisfaction, eg. an enquiry or document delivery service.

Above all, benchmarking is one of a range of tools which can be used within a quality management framework. A high level of commitment from senior management is therefore essential, if it is to succeed. All levels of staff should be involved with a team working approach high on the agenda. Above all a policy of openness is required. Only in this way can information be shared with others -with learning and improving existing service levels the common goal.

\section{Methodology}

\section{i. Questionnaire survey}

Questionnaires were sent out to academic libraries, and to a sample of industrial library and information services. Results are currently being analyzed, but the response rate for academic libraries now stands at $75 \%$. Replies from the commercial sector are still coming in; the response rate is now $32 \%$.

The questionnaire will help determine current levels of activity in the field of quality management 
in the LIS sector, and identify perceptions of benchmarking. Results from the first tranche of respondents reveal a high level of awareness amongst the academic sector, although levels of implementation are low. In general, library and information services use informal methods of quality management, and do not have formal written policies on quality.

Popular initiatives include:

- Team working - almost $60 \%$ of respondents have implemented this

- Performance Indicators - over 50\% of respondents state that these are either currently used, or are in preparation

- Investors In People - $20 \%$ have introduced this initiative

Follow-up telephone interviews are now being conducted with a selection of those libraries and information services which indicated a willingness to take part. This interview stage will add further data; it emphasizes the significance of perceptions for the implementation of benchmarking techniques.

\section{ii. Demonstrator projects}

Three library and information services, from different sectors of the LIS community, have volunteered to undertake a benchmarking exercise on behalf of the project. They have chosen to benchmark processes which they perceive to be paramount to the effectiveness of their particular organizations. The chosen processes need to be easy to measure, enabling comparisons with similar processes in other organizations to be carried out. Possible benchmarking partners are being sought - with a view to evaluating and sharing information on performance and procedures. The process of recording and evaluating a service in itself may lead to heightened awareness of procedural shortcomings. It is anticipated that participants will benefit from the exercise. The act of allocating precious time in hectic schedules, in order to carry out the necessary monitoring and recording of current activities, is a key step in the benchmarking process. Problems areas, such as delays due to various factors, can then be identified and analyzed, and comparison and exchange of ideas with other organizations will present ideal learning opportunities.

\section{iv. Dissemination of information}

A select bibliography on Quality Management has been compiled, which will be published shortly. The aim of this bibliography is to offer managers in the library and information sector a guide to a selection of the literature available. It comprises around 200 items organized under twelve headings which include Total Quality Management, Performance Indicators and Benchmarking. There is a wealth of literature available on quality issues, much of which is repetitive and highly theoretical, and the need for such a guide, aimed specifically at the profession, was identified.

Reports will be published at various stages in the project. These will include a paper reflecting the state-of-the-art in quality management for the library and information sectors in Europe. It will include networking possibilities and will list organizations involved in quality management.

A final British Library Research and Development Report will also be published towards the end of the project, which will draw together the various findings from the questionnaire and telephone surveys, the demonstrator projects, and other methodologies used throughout the research. A benchmarking workshop is also planned towards the end of the project. 


\title{
References
}

1. Bendell, T. et al. Benchmarking for competitive advantage. London: Pitman Publishing, 1993

2. First Find Your Bench. Economist, 11 May 1991, p.102.

3. DTI. Managing in the '90s. Best practice benchmarking: an executive guide. DTI, 1994, p.1.

4. Coopers and Lybrand. Survey of benchmarking in the UK. Coopers and Lybrand and the Confederation of British Industry, 1993, p.5.

\section{Developing an effective questionnaire}

\author{
ANNE RUSSELL \\ IME Ltd \\ $\underline{\text { and }}$ \\ MICHAEL SHOOLBRED \\ School of Information Studies \\ University of Central England
}

\section{Summary}

This article describes a project to study the usage patterns of public library services by students of Adult Basic Education (ABE). The article focuses on how the survey instrument was developed and offers some suggestions on questionnaire design. It will be of interest to researchers working with any group for whom completing a questionnaire might be a struggle.

\section{Introduction}

This article has been written for new researchers who are about to embark upon a survey and are interested in techniques to obtain high response rates and valid data. It should be of particular relevance to those who carry out surveys of groups which might include individuals with reading difficulties or others who would not readily complete a questionnaire.

The project stemmed for some MA research carried out by Anne Russell at the University of Central England in $1993^{(1)}$. The project investigated the usage patterns of public library services by $\mathrm{ABE}$ students, the aim of the research being to give public librarians new information about an important and poorly documented group - students of adult basic education $(\mathrm{ABE})$.

These are students who do not possess functional literacy, and therefore have major problems with such everyday literacy skills as writing a cheque, or reading a shopping list. Numeracy as well as literacy is included within the term ABE. These individuals are students because they are participating in $\mathrm{ABE}$ schemes, day classes or evening classes at ABE Centres designed to help them to develop their literacy and numeracy skills. Where do libraries come in? Some libraries have a close liaison with their local ABE Centres, and aim to provide materials, resource packs and cooperative ventures with tutors. Additionally, some $\mathrm{ABE}$ students will want to use libraries of 